\title{
Identification of a Novel MicroRNA Panel Associated with Metastasis Following Radical Prostatectomy for Prostate Cancer
}

\author{
ROBERT K. NAM ${ }^{1}$, CHRISTOPHER J.D. WALLIS ${ }^{1}$, YUTAKA AMEMIYA ${ }^{2}$, \\ TANIA BENATAR ${ }^{3,4}$ and ARUN SETH ${ }^{2,3,4,5}$ \\ ${ }^{1}$ Division of Urology, Sunnybrook Health Sciences Centre, \\ Sunnybrook Research Institute, University of Toronto, Toronto, Canada; \\ ${ }^{2}$ Sunnybrook Research Institute Genomics Facility, Toronto, Canada; \\ ${ }^{3}$ Department of Laboratory Medicine and Pathobiology, University of Toronto, Toronto, Canada; \\ ${ }^{4}$ Platform Biological Sciences, Sunnybrook Health Sciences Centre, \\ Sunnybrook Research Institute, University of Toronto, Toronto, Canada; \\ ${ }^{5}$ Faculty of Dentistry, University of Toronto, Toronto, Canada
}

\begin{abstract}
Background/Aim: This is a case control study designed to identify one or more novel microRNA sequences associated with metastasis following radical prostatectomy for clinically localized prostate cancer. Materials and Methods: Samples were obtained from patients with clinical evidence of metastatic disease following surgery (cases) and patients who showed no evidence of metastasis or biochemical recurrence at least 5 years following surgery (controls) as identified from a single-center, institutional database. Cases and controls were matched for tumor grade and duration of follow-up. Results: Whole miRNome analysis identified 2,792 expressed miRNAs in 19 patient pairs. The 497 miRNA sequences with reads per million over 10, were used for analysis, bootstrapping with backward selection identified a panel of 5-miRNA (miR-17-3p, miR-27a-3p, miR-200a-3p, miR-375, and miR-376b-3p) with a risk score strongly associated with metastasis (AUC $=89.5 \%$, 95\%CI=79.5-99.5\%). Methodologically, most studies use the magnitude of differential expression with or without clinical judgement for selection of predictors for inclusion in panels. In order to strengthen the predictive model, a selection strategy was employed, bootstrapping with automated backwards selection, which relied on the strength of association for
\end{abstract}

This article is freely accessible online.

Correspondence to: Professor Arun Seth, Sunnybrook Health Sciences Centre 2075 Bayview Avenue, Room S238, Toronto, Ontario, M4N 3M5, Canada. Tel: +1 4164806100, ext. 3536, Fax: +1 4164805737, e-mail: arun.seth@utoronto.ca

Key Words: Prostate cancer, prostatectomy, metastasis, recurrence, miRNome, microRNA. inclusion. Conclusion: A genome-wide analysis of microRNA expression identified a panel of 5 miRNAs strongly associated with prostate cancer metastasis following radical prostatectomy.

Patients with clinically localized prostate cancer may experience a wide spectrum of phenotypes, ranging from indolent tumors which will never require treatment to highly aggressive and lethal disease. Distinguishing between these two phenotypes remains one of the most important questions in the management of these patients. Current prognostic factors including tumor stage, histological grade (Gleason score), and pre-operative serum prostate specific antigen (PSA) levels are insufficient to accurately predict patient outcomes $(1,2)$.

MicroRNAs (miRNAs) are a class of small non-coding RNA which modulate messenger RNA (mRNA) expression through direct binding. The 5' end of the miRNA binds via a targeting "seed" region to a complementary sequence in the 3' mRNA transcript. The strength of this bond depends on the sequence and number of seeds. For the most part, miRNA-mRNA interactions result in down-regulation though a small number cause either up-regulation or complete destruction of the mRNA target.

The role of miRNA in cancer was first demonstrated in leukemia. Since then, it has been discovered that altered expression of miRNA contributes to most, if not all, human cancers. Furthermore, it has been found that miRNA may either initiate carcinogenesis or drive disease progression (3).

MiRNA expression is dynamic and both miRNA and target expression may vary within the same cell depending on time or circumstance. This allows for significant signal amplification as a single protein may act via a small number of miRNAs to influence many genes (4). 
Alterations in miRNA expression may themselves be driven by either genetic or epigenetic changes. Many miRNAs are located in genetically unstable sites where they are prone to deletion or rearrangement, as observed in cancer (5). In addition, miRNA function may be affected by mRNA mutation in the target site. Epigenetically, many miRNA genes are located next to $\mathrm{CpG}$ islands where they may be prone to epigenetic silencing. This phenomenon has been documented to be relevant in urologic malignancy (6-9).

Molecular prognostic factors have significantly altered the management of patients with many solid tumors. MicroRNAs (miRNAs), small non-coding RNA which modulate messenger RNA expression, have shown promise as prognostic biomarkers in many cancers (10-13). Numerous groups have examined the prognostic role of miRNA in prostate cancer (14-19). However, no miRNAs or miRNA-based panels have yet transitioned to clinical use. This study aimed to identify a panel of miRNAs that were predictive of the development of metastasis following radical prostatectomy for patients with clinically localized prostate cancer.

\section{Materials and Methods}

Study design. This study was conducted with the approval of Sunnybrook Health Sciences Centre research ethics board. A matched case-control study was conducted in order to identify a novel panel of microRNA sequences which could predict metastasis following radical prostatectomy. Cases were patients who developed metastasis following radical prostatectomy and controls were patients who were cancer-free following surgery.

Data sources and study population. A well-established, institutional research ethics board approved database of 585 patients was utilized. Patients were treated with radical prostatectomy for clinically-localized prostate cancer between 1990 and 2000 at Sunnybrook Health Sciences Centre, a single, tertiary care hospital. Written, informed consent was obtained from all patients for the use of biological materials and clinical information. Trained data abstractors systematically reviewed each patient's medical record. Standardized data entry forms were used to compile an institutional, prostate cancer-specific database. Within this database, metastasis was defined as evidence of bony lesions identified on radionuclide bone scan or evidence of extra-pelvic lymphadenopathy or visceral lesions on computed tomography imaging of the abdomen, pelvis and chest.

Within this dataset, patients diagnosed with metastases following surgery were identified. Patients with metastases were matched to patients with no evidence of disease recurrence (i.e. no metastasis and no biochemical recurrence) based on a hard match comprising Gleason score from radical prostatectomy and duration of followup. Inclusion of other variables in the matching process, including pathological stage, nodal status, pre-operative prostate specific antigen (PSA) and margin status, resulted in insufficient matches for analysis. Gleason score was selected for matching as it is the strongest independent predictor of recurrence and metastasis (20). Patients who developed metastasis following radical prostatectomy who were unable to be matched to a suitable control were excluded. Similarly, where there was insufficient biological sample for analysis, the pair was excluded.

Whole miRNome analysis. For each patient selected, genito-urinary pathologists re-reviewed the formaldehyde-fixed paraffin-embedded (FFPE) radical prostatectomy specimen. A representative slide was selected and the corresponding tumor block was identified. The largest tumor focus was identified and a sample was collected by punching using a $1.0 \mathrm{~mm}$ Tissue MicroArray coring needle from the area of the FFPE block with the highest tumor-to-stroma ratio.

RNA extraction and small RNA enrichment. Two FFPE cores per sample with a diameter of $1 \mathrm{~mm}$ and a maximum length of $3 \mathrm{~mm}$ (after trimming of excess paraffin) were used for total RNA extraction. FFPE cores were manually pulverized in a $1.5 \mathrm{ml}$ conical tube using plastic pellet pestles. Total RNA was then extracted using the RecoverAll Total Nucleic Acid Isolation Kit for FFPE (ThermoFisher Scientific, Waltham, MA, USA) in accordance with the manufacturer's manuals. The concentration and integrity of the extracted total RNA was ascertained using Qubit 2.0 fluorometer with Qubit RNA HS Assay kit (ThermoFisher Scientific) and Agilent 2100 Bioanalyzer with RNA6000 Nano chip (Agilent Technologies, Santa Clara, CA, USA), respectively. The small RNA fraction was enriched from $1 \mu \mathrm{g}$ of extracted RNA using the Magnetic Beads Cleanup Module (ThermoFisher Scientific). All procedures were carried out in accordance with the manufacturer's manuals. The quality and quantity of samples that were enriched for small RNA were assessed by Agilent 2100 Bioanalyzer with the Small RNA chip (Agilent Technologies).

cDNA library construction. Complementary DNA (cDNA) libraries were constructed from the enriched small RNA using the Ion Total RNA-Seq Kit v2 (ThermoFisher Scientific), in accordance with the manufacturer's manuals. Ion Adaptor Mix v2 were hybridized and then ligated to small RNA followed by reverse transcription to generate a cDNA library. The cDNA products were purified and size-selected with the Magnetic Beads Cleanup Module and then PCR amplified with barcoded primers for 14 cycles. The barcoded cDNA libraries were purified and size-selected with the Magnetic Beads Cleanup Module and the yield and size distribution of cDNA libraries were assessed by Agilent 2100 Bioanalyzer with the High Sensitive DNA chip (Agilent Technologies).

Ion S5XL sequencing and data analysis. The barcoded cDNA libraries were diluted to $30 \mathrm{pM}$ and 8 libraries were pooled for each run. Template-positive ion sphere particles containing clonally amplified DNA were generated and enriched using the Ion 540 Chef kit with the Ion Chef instrument (ThermoFisher Scientific). Ion Torrent sequencing was performed for 160 flows on an Ion S5XL Sequencer with Ion 540 Chips.

Ion Torrent platform-specific pipeline software (Torrent Suite version 5.0.4; ThermoFisher Scientific) was used to remove polyclonal, low quality and adapter dimer reads and then separate barcoded reads for each sample. Ion Torrent platform-specific Small RNA Analysis plug-in (v5.0.5) was used to analyze micro RNA reads. Reads were aligned to mature micro RNAs (mirBase build 21) using bowtie 2 aligners. Unmapped reads were further aligned to the hg19 Human genome reference to rescue miRbase unaligned reads and count other RNA molecules. The miRNA expression levels were 


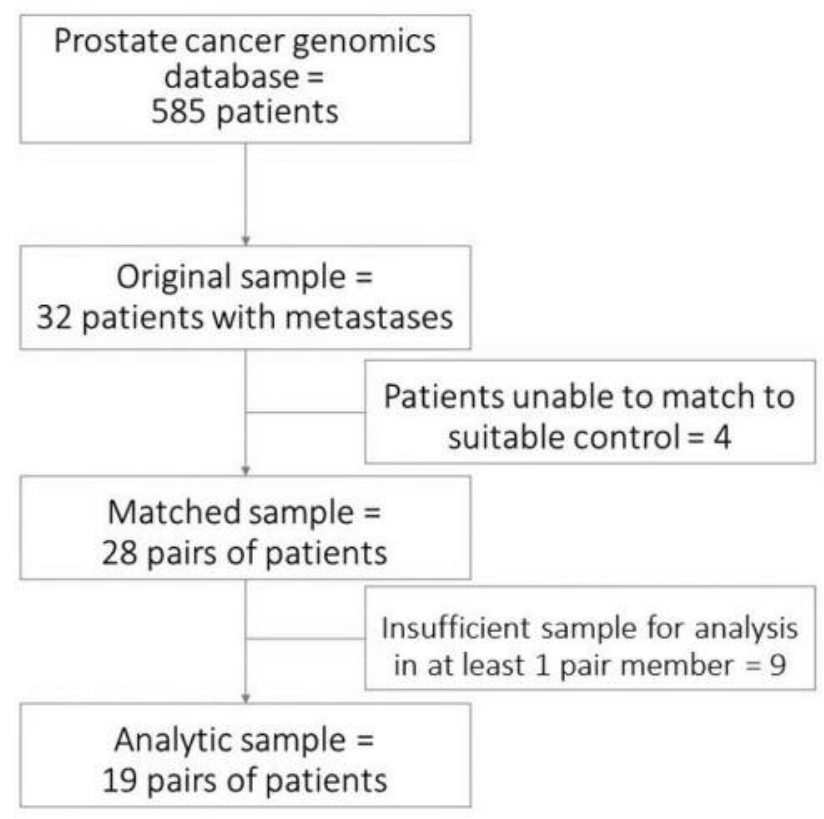

Figure 1. Prostate cancer analytic cohort used in this study was comprised of 19 matched pairs and was derived from a cohort of 585 patients.

quantified as the number of reads mapped to individual miRNAs normalized by the total number of mapped reads in miRBase per sample. Sequences have been deposited in the Gene Expression Omnibus (GEO) database, https://www.ncbi.nlm.nih.gov/geo (accession no GSE117674).

Statistical analysis. Baseline characteristics were described using medians and interquartile ranges for continuous variables and proportions for categorical variables. Patients who developed metastasis and controls were compared using the Wilcoxon rank sum test for continuous variables and Fisher's exact test for categorical variables.

We then undertook variable selection in order to identify miRNA sequences which were significantly differentially expressed between patients who developed metastasis and controls using bootstrapping with automated backward selection (21). To do this, first, sequences where the mean reads per million (RPM) was less than 10 for both cases and controls were excluded as sequences with these low expression levels are unlikely to provide reproducible results (20). Second, screening was performed: sequences which were associated with metastasis with a $p<0.05$ on univariate logistic regression models were identified. Among the sequences identified on screening, multivariable logistic regression with backwards selection was conducted to identify significant independent predictors of metastasis. Variables were retained in the model if the significance of association was $p<0.05$. Bootstrapping (sampling with replacement for a total sample of $N$ ) for a total of 1000 repetitions was performed (21). The frequency with which each sequence was included in the predicted models was identified. Sequences which were maintained in greater than 100 samples were considered important predictors.
Table I. Baseline demographic characteristics of patients in the discovery cohort.

\begin{tabular}{lccc}
\hline & $\begin{array}{c}\text { Controls } \\
\text { (no metastasis) }\end{array}$ & $\begin{array}{c}\text { Cases } \\
\text { (metastasis) }\end{array}$ & $p$-Value \\
\hline Sample (n) & 19 & 19 & \\
Age (median, IQR) & $63.9(61.7-67.0)$ & $62.7(59.1-67.6)$ & 0.54 \\
Gleason score (n,\%) & & & 1.00 \\
6 & $1(5.3)$ & $1(5.3)$ & \\
7 & $8(42.1)$ & $8(42.1)$ & \\
$8-10$ & $10(52.6)$ & $10(52.6)$ & \\
Pathological Stage (n,\%) & $11(57.9)$ & $1(5.3)$ & \\
T2 & $8(42.1)$ & $18(94.7)$ & \\
T3 & $6(31.6)$ & $10(52.6)$ & \\
Nodal status (n,\%) & 0 & $5(26.3)$ & \\
Negative & $13(68.4)$ & $4(21.1)$ & \\
Positive & $8(42.1)$ & $10(52.6)$ & 0.0006 \\
$\quad$ Missing & $7.3(4.0-10.0)$ & $10.0(4.3-15.1)$ & 0.30 \\
Positive margins (n, $\%)$ & \\
PSA (median, IQR) & & & \\
\hline
\end{tabular}

Among the selected sequences identified using bootstrapping with automated backward selection, it was examined whether a parsimonious combination could be identified. The predictive ability of each combination of sequences was compared using the Score criterion (higher Score considered better).

Using the combination of variables identified previously, a risk score was developed using the linear combination of the expression level of each selected miRNA sequence, weighted by the regression coefficient derived from a univariate logistic regression model (12, 13). All statistical analyses were performed using SAS 9.4 (SAS Institute Inc., Cary, NC, USA).

\section{Results}

Overall, 32 patients who developed metastasis following radical prostatectomy were identified. Of these, 28 were matched to a control based on Gleason score and duration of follow-up and 4 were excluded due to an inability to identify a suitable match. Of the 28 matched pairs, there was an insufficient sample for analysis in at least one member of 9 pairs. Thus, the analytic cohort comprised 19 matched pairs (Figure 1). A greater proportion of patients who developed metastasis following radical prostatectomy had pathological stage T3 disease and positive lymph nodes (Table I). Among patients who developed metastasis, the median time to metastasis following radical prostatectomy was 4.84 years (interquartile range $=2.34-7.75$ years).

A total of 2,792 miRNAs were identified which were expressed in the prostate tumors of patients in the analytic cohort. Of these, 1920 had very low levels of expression in both cases and controls (less than 1 RPM) and a further 375 had low levels of expression in both groups (RPM between 
Table II. Expression level (RPM) of five miRNA identified to predict metastasis.

\begin{tabular}{lccc}
\hline MiRNA sequence & $\begin{array}{c}\text { Controls } \\
\text { (no metastasis) }\end{array}$ & $\begin{array}{c}\text { Cases } \\
\text { (metastasis) }\end{array}$ & $\begin{array}{c}\text { Differential } \\
\text { expression }\end{array}$ \\
\hline miR200a_3p & 2288.8 & 5340.88 & 2.33 \\
miR375 & 6849.91 & 12278.4 & 1.79 \\
miR376b_3p & 12.2533 & 20.6362 & 1.68 \\
miR17_3p & 195.04 & 323.011 & 1.66 \\
miR27a_3p & 4004.76 & 5350.32 & 1.34 \\
\hline
\end{tabular}

1 and 10). Therefore, 497 unique miRNA sequences with RPM $>10$ were used for further analysis.

Bootstrapping with backward selection was then performed to identify predictors of metastasis. On univariate screening, 99 sequences were associated with metastasis with a $p$-value $<0.05$. Based on bootstrapping with 1000 repetitions, 28 miRNA sequences were retained in at least one sample, 21 sequences were retained in at least 50 samples and 5 miRNA were retained in at least 100 samples. The five selected miRNA sequences were miR-17-3p, miR-27a-3p, miR-200a$3 p$, miR-375, and miR-376b-3p. Each of these sequences was up-regulated in patients who developed metastasis as compared to those who remained cancer-free (Table II).

All possible permutations of the five miRNA were examined in order to ascertain if a parsimonious panel could be identified. The combination of five miRNA had the highest Score criterion, indicating that this combination resulted in the greatest predictive ability (Table III).

A risk score was then derived based on the linear combination of the expression level of each selected miRNA sequence, weighted by the regression coefficient derived from a univariate logistic regression model $(12,13)$. The risk score was:

$(0.00635 \times \mathrm{miR}-17-3 \mathrm{p})+(0.000548 \times \mathrm{miR}-27 \mathrm{a}-3 \mathrm{p})$

$+(0.000466 \times \mathrm{miR}-200 \mathrm{a}-3 \mathrm{p})+$

$(0.000144 \times$ miR-375) $+(0.1121 \times$ miR-376b-3p $)$.

This miRNA panel yielded an area under the curve (AUC) of $89.5 \%(95 \% \mathrm{CI}=79.5-99.5 \%)$ to predict prostate cancer metastasis (Figure 2).

\section{Discussion}

In this study, a novel panel of miRNA comprising miR-17, miR-27a, miR-200a, miR-375, and miR-376b was identified, which is strongly associated with the development of metastasis following surgery for localized prostate cancer (AUC 89.5\%). Each of the miRNAs identified for inclusion in the panel has previously been associated with carcinogenesis, though not all have been associated with prostate

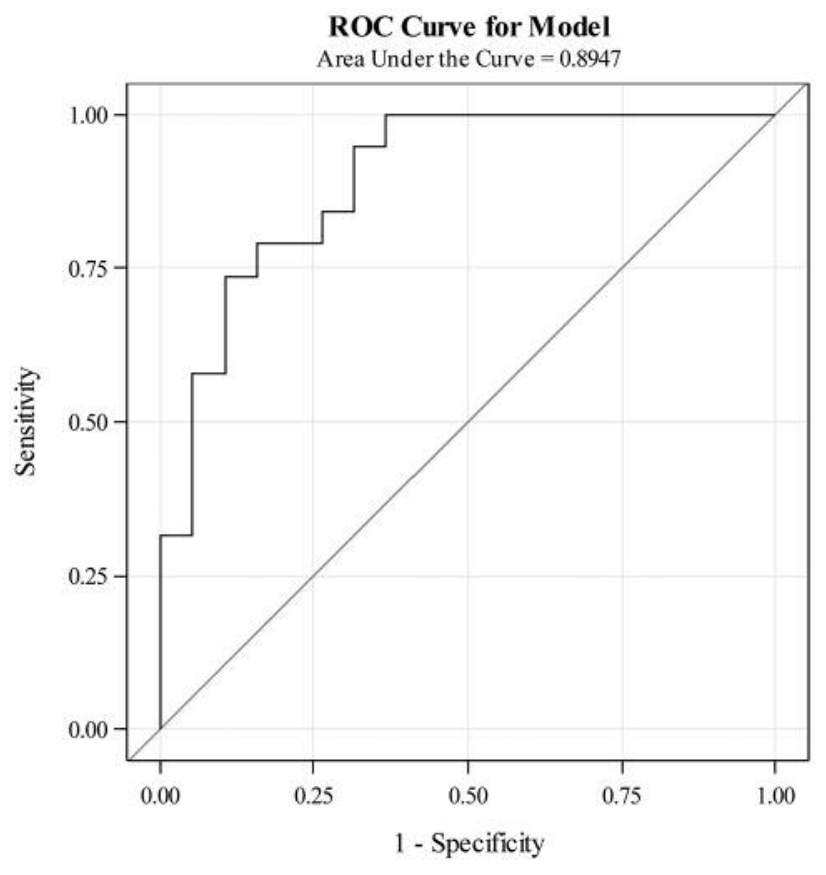

Figure 2. A risk score based on the linear combination of the expression level of each selected miRNA sequence was weighted by the regression coefficient derived from a univariate logistic regression model. The 5-miRNA panel yielded an area under the curve of $89.5 \%$ $(95 \% C I=79.5-99.5 \%)$ to predict prostate cancer metastasis.

carcinogenesis. MiR-375 is well-described in the carcinogenesis and progression pathways of prostate cancer $(22,23)$ as well as pancreatic ductal adenocarcinomas (24) and has been proposed as both a diagnostic (25) and a prognostic (26) biomarker for prostate cancer. Increased expression of miR-375 has been found in prostate cancer cells, as compared to normal cells $(22,23)$, indicating a pro-oncogenic role despite it's anti-invasive and anti-epithelial-mesenchymal transition properties (27). Further, upregulation of miR-375 has been shown to be associated with disease recurrence in breast cancer (28). In contrast, decreased expression of miR-375 has been associated with many other tumor sites including hepatocellular carcinoma, gastric cancer, esophageal cancer, head and neck cancers, lung cancer, and cervical cancer indicating a tumor suppressor role at these sites (29). MiR-17-3p and its corresponding mature strand have been shown to enhance prostate tumor growth and invasion through the suppression of TIMP metallopeptidase inhibitor 3 (TIMP3) (30). Further work has shown that miR-17 may act in the carcinogenesis process of hepatocellular carcinoma (31), gallbladder cancer (32), glioblastoma (33), breast cancer (34), and colorectal cancer (35). However, others have shown that miR-17-3p may act as a tumor suppressor in prostate cancer (36). It was found that miR-17-3p was over-expressed in the tumors of patients who 
Table III. All possible regression models using five miRNA sequences identified by bootstrapping with backward selection.

\begin{tabular}{|c|c|c|}
\hline $\begin{array}{l}\text { Number of } \\
\text { variables }\end{array}$ & $\begin{array}{l}\text { Score } \\
\text { criterion }\end{array}$ & Variables Included in Model \\
\hline 5 & 15.9406 & $\begin{array}{c}\text { miR-200a-3p miR-375 miR-376b-3p } \\
\text { miR-17-3p miR-27a-3p }\end{array}$ \\
\hline 4 & 15.5868 & $\begin{array}{c}\text { miR-200a-3p miR-375 } \\
\text { miR-376b-3p miR-27a-3p }\end{array}$ \\
\hline 4 & 15.1226 & $\begin{array}{l}\operatorname{miR}-200 a-3 p \text { miR-375 } \\
\text { miR-376b-3p miR-17-3p }\end{array}$ \\
\hline 4 & 14.5503 & $\begin{array}{l}\operatorname{miR}-200 a-3 p \text { miR-375 } \\
\text { miR-17-3p miR-27a-3p }\end{array}$ \\
\hline 3 & 14.4445 & miR-200a-3p miR-375 miR-376b-3p \\
\hline 3 & 14.3435 & miR-200a-3p miR-375 miR-27a-3p \\
\hline 4 & 14.3236 & $\begin{array}{l}\text { miR-375 miR-376b-3p } \\
\text { miR-17-3p miR-27a-3p }\end{array}$ \\
\hline 4 & 13.4773 & $\begin{array}{c}\text { miR-200a-3p miR-376b-3p } \\
\text { miR-17-3p miR-27a-3p }\end{array}$ \\
\hline 3 & 13.4388 & miR-375 miR-376b-3p miR-17-3p \\
\hline 3 & 12.854 & miR-200a-3p miR-376b-3p miR-17-3p \\
\hline 3 & 12.5932 & miR-375 miR-17-3p miR-27a-3p \\
\hline 3 & 12.4601 & miR-200a-3p miR-376b-3p miR-27a-3p \\
\hline 3 & 12.4207 & miR-375 miR-376b-3p miR-27a-3p \\
\hline 3 & 11.7461 & miR-376b-3p miR-17-3p miR-27a-3p \\
\hline 3 & 11.6345 & miR-200a-3p miR-17-3p miR-27a-3p \\
\hline 3 & 11.5436 & miR-200a-3p miR-375 miR-17-3p \\
\hline 2 & 11.3916 & miR-200a-3p miR-376b-3p \\
\hline 2 & 11.0667 & miR-376b-3p miR-17-3p \\
\hline 2 & 10.9695 & miR-375 miR-27a-3p \\
\hline 2 & 10.8897 & miR-200a-3p miR-375 \\
\hline 2 & 10.8624 & miR-200a-3p miR-27a-3p \\
\hline 2 & 10.5273 & miR-375 miR-376b-3p \\
\hline 2 & 9.482 & miR-17-3p miR-27a-3p \\
\hline 2 & 9.0914 & miR-375 miR-17-3p \\
\hline 2 & 8.7627 & miR-200a-3p miR-17-3p \\
\hline 2 & 7.9928 & miR-376b-3p miR-27a-3p \\
\hline 1 & 7.242 & miR-200a-3p \\
\hline 1 & 6.1081 & miR-17-3p \\
\hline 1 & 6.0519 & $\operatorname{miR}-376 b-3 p$ \\
\hline 1 & 6.022 & $\operatorname{miR}-27 a-3 p$ \\
\hline 1 & 5.647 & $\operatorname{miR}-375$ \\
\hline
\end{tabular}

developed metastasis (differential expression 1.66). Thus, further work is necessary to understand its role in prostate carcinogenesis. Similar complexity exists for miR-27a-3p. While, to our knowledge, there are no studies linking changes in $\mathrm{miR}-27 \mathrm{a}-3 \mathrm{p}$ expression to prostate carcinogenesis, there is evidence that it functions in promoting the development and progression of other urologic malignancies including renal cell carcinoma (37) and bladder cancer $(38,39)$ in addition to other tumors including gastric cancer (40), esophageal cancer (41), pancreatic cancer (42), colorectal cancer (43), and glioma (44). However, in hepatocellular carcinoma, miR-27a-3p appears to have a tumor suppressive role (45). Again, we demonstrated increased expression in patients who developed metastatic disease (differential expression 1.34). Similar to miR-27a-3p, there are no studies assessing the association between miR200a-3p expression and prostate carcinogenesis. Mir-200a-3p appears to be involved in the development and progression of gastric cancer (46), hepatocellular carcinoma (47), lung cancer (48), colorectal cancer (49), HPV-induced tonsillar cancer (50), while it suppresses development of renal cell carcinoma (51) and is negatively correlated with the aggressiveness of gliomas (52). Further, miR-200a-3p may play a role in the development of chemotherapy resistance (53). MiR-200a-3p has also been implicated in the development of polycystic ovarian syndrome (54). Finally, we are unaware of any direct associations between miR-376b-3p expression and prostate cancer or general carcinogenesis. Among three studies returned on a PubMed search for "miR-376b-3p" were manuscripts demonstrating its usefulness as a biomarker for periodontitis (55), its down-regulation in mouse models of chronic obstructive pulmonary disease (56), and its role in the central nervous system response to hypoxia (57). While these citations are seemingly oblique to carcinogenesis, miR-376b-3p is associated with TGF- $\beta 1$ which is a well-recognized initiator and regulator of epithelial-mesenchymal transition (58). TGF$\beta 1$ has been directly implicated in prostate cancer treatment response and prognostication $(59,60)$. Of the identified miRNAs, miR-17 and miR-27a have previously been included in predictive panels for colon cancer diagnosis and prognosis $(35,43)$ and miR-375 has been included in a panel for prostate cancer diagnosis, but not prognostication (25).

Previous studies have identified miRNAs which may be important in prostate cancer prognosis (14-19). However, these have not been used in routine clinical practice. This likely reflects at least two issues: first, validation of the findings and secondly, the use of biochemical recurrence, a surrogate outcome. Kristensen et al. have recently published their work identifying miRNAs for prostate cancer diagnosis and prognosis (61). Following derivation in a discovery cohort, they validated their findings in an independent group of patients within their institution (validation cohort 1) using a publicly available dataset (validation cohort 2) (61). They identified a panel of three miRNA (miR-185-5p, miR-221$3 p$, and miR-326) for prognosis. As with other authors, they used biochemical recurrence as an outcome. While this is appealing due to its relatively high frequency and early appearance (62), only a small percentage of men with biochemical recurrence will have systemic progression or die of their disease (63). Thus, metastasis, as used in our study, is a more clinically-relevant endpoint. In our previous study examining miRNA for prostate cancer prognostication, we considered a composite endpoint of biochemical recurrence and metastasis in our discovery cohort (20). While this panel was independently prognostic of metastases (20), further study showed that many of the miRNA included in the panel 
were more strongly associated with biochemical recurrence than metastasis (64).

Such a panel, once validated, may allow for the provision of appropriate subsequent therapies after surgery. In a similar vein, Zehentmayr et al. have proposed the use of miR-375 expression levels to guide post-operative therapy following breast conserving surgery (28). Future research will be undertaken to assess whether this panel can be applied to transrectal-ultrasound guided prostate biopsy tissue or serum samples in order to risk stratify patients prior to local treatment.

There are limitations to the use of miRNA profiling from prostate cancer tissue. Foremost is the intra-tumoral heterogeneity among tumor foci. Most patients with prostate cancer have tumor foci with varying Gleason scores. We (20), and others $(65,66)$, have shown that miRNA expression varies by Gleason grade. Further study is required to determine the best method to identify representative samples for miRNA profiling. In this study, a section of the largest tumor with the highest tumor-to-stroma ratio was used. Kristensen et al. employed a similar strategy selecting representative areas with $>90 \%$ tumor involvement (61). Methodologically, most studies use the magnitude of differential expression, with or without clinical judgement, for selection of predictors for inclusion in panels. As we sought to develop a strongly predictive model, we employed a selection strategy, bootstrapping with automated backwards selection, which relied on the strength of association for inclusion.

\section{Conclusion}

Using a genome-wide analysis of microRNA expression, a novel panel of five microRNA that is associated with prostate cancer metastasis following radical prostatectomy was identified.

\section{Acknowledgements}

This study was funded in part by the Edmond Odette Foundation, the Ajmera Family Chair in Urologic Oncology, and a generous philanthropic contribution from Archie and Betty McCallum.

\section{References}

1 Jung JW, Lee JK, Hong SK, Byun SS and Lee SE: Stratification of patients with intermediate-risk prostate cancer. BJU Int 115(6): 907-912, 2015.

2 Siadat F, Sykes J, Zlotta AR, Aldaoud N, Egawa S, Pushkar D, Kuk C, Bristow RG, Montironi R and van der Kwast T: Not all gleason pattern 4 prostate cancers are created equal: A study of latent prostatic carcinomas in a cystoprostatectomy and autopsy series. Prostate 75(12): 1277-1284, 2015.

3 Croce CM: Causes and consequences of microRNA dysregulation in cancer. Nat Rev Genet 10(10): 704-714, 2009.
4 Catto JW, Alcaraz A, Bjartell AS, De Vere WR, Evans CP, Fussel S, Hamdy FC, Kallioniemi O, Mengual L, Schlomm T and Visakorpi T: MicroRNA in prostate, bladder, and kidney cancer: a systematic review. Eur Urol 59(5): 671-681, 2011.

5 Lamy P, Andersen CL, Dyrskjot L, Torring N, Orntoft T and Wiuf C: Are microRNAs located in genomic regions associated with cancer? Br J Cancer 95(10): 1415-1418, 2006.

6 Dudziec E, Miah S, Choudhry HM, Owen HC, Blizard S, Glover $\mathrm{M}$, Hamdy FC and Catto JW: Hypermethylation of CpG islands and shores around specific microRNAs and mirtrons is associated with the phenotype and presence of bladder cancer. Clin Cancer Res 17(6): 1287-1296, 2011.

7 Rauhala HE, Jalava SE, Isotalo J, Bracken H, Lehmusvaara S, Tammela TL, Oja $\mathrm{H}$ and Visakorpi $\mathrm{T}$ : $\mathrm{miR}-193 \mathrm{~b}$ is an epigenetically regulated putative tumor suppressor in prostate cancer. Int J Cancer 127(6): 1363-1372, 2010.

8 Varambally S, Cao Q, Mani RS, Shankar S, Wang X, Ateeq B, Laxman B, Cao X, Jing X, Ramnarayanan K, Brenner JC, Yu J, Kim JH, Han B, Tan P, Kumar-Sinha C, Lonigro RJ, Palanisamy N, Maher CA and Chinnaiyan AM: Genomic loss of microRNA-101 leads to overexpression of histone methyltransferase EZH2 in cancer. Science 322(5908): 16951699, 2008.

9 Wiklund ED, Bramsen JB, Hulf T, Dyrskjot L, Ramanathan R, Hansen TB, Villadsen SB, Gao S, Ostenfeld MS, Borre M, Peter ME, Ørntoft TF, Kjems J and Clark SJ: Coordinated epigenetic repression of the miR-200 family and miR-205 in invasive bladder cancer. Int J Cancer 128(6): 1327-1334, 2011.

10 Bagnoli M, Canevari S, Califano D, Losito S, Maio MD, Raspagliesi F, Carcangiu ML, Toffoli G, Cecchin E, Sorio R, Canzonieri V, Russo D, Scognamiglio G, Chiappetta G, Baldassarre G, Lorusso D, Scambia G, Zannoni GF, Savarese A, Carosi M, Scollo P, Breda E, Murgia V, Perrone F, Pignata S, De Cecco L and Mezzanzanica D: Development and validation of a microRNA-based signature (MiROvaR) to predict early relapse or progression of epithelial ovarian cancer: a cohort study. Lancet Oncol 17(8): 1137-1146, 2016.

11 Hartz JM, Engelmann D, Furst K, Marquardt S, Spitschak A, Goody D, Protzel C, Hakenberg OW and Pützer BM: Integrated Loss of miR-1/miR-101/miR-204 Discriminates Metastatic from Nonmetastatic Penile Carcinomas and Can Predict Patient Outcome. J Urol 196(2): 570-578, 2016.

12 Lossos IS, Czerwinski DK, Alizadeh AA, Wechser MA, Tibshirani R, Botstein D and Levy R: Prediction of survival in diffuse large-B-cell lymphoma based on the expression of six genes. N Engl J Med 350(18): 1828-1837, 2004.

13 Yu SL, Chen HY, Chang GC, Chen CY, Chen HW, Singh S, Cheng CL, Yu CJ, Lee YC, Chen HS, Su TJ, Chiang CC, Li HN, Hong QS, Su HY, Chen CC, Chen WJ, Liu CC, Chan WK, Chen WJ, Li KC, Chen JJ and Yang PC: MicroRNA signature predicts survival and relapse in lung cancer. Cancer Cell 13(1): 48-57, 2008.

14 Casanova-Salas I, Rubio-Briones J, Calatrava A, Mancarella C, Masia E, Casanova J, Fernández-Serra A, Rubio L, Ramírez-Backhaus M, Armiñán A, Domínguez-Escrig J, Martínez F, García-Casado Z, Scotlandi K, Vicent MJ and López-Guerrero JA: Identification of miR-187 and miR-182 as biomarkers of early diagnosis and prognosis in patients with prostate cancer treated with radical prostatectomy. J Urol 192(1): 252-259, 2014 
15 Formosa A, Markert EK, Lena AM, Italiano D, Finazzi-Agro' E, Levine AJ, Bernardini S, Garabadgiu AV, Melino G and Candi E: MicroRNAs, miR-154, miR-299-5p, miR-376a, miR-376c, miR-377, miR-381, miR-487b, miR-485-3p, miR-495 and miR654-3p, mapped to the $14 q 32.31$ locus, regulate proliferation, apoptosis, migration and invasion in metastatic prostate cancer cells. Oncogene 33(44): 5173-5182, 2014.

16 Lichner Z, Fendler A, Saleh C, Nasser AN, Boles D, Al-Haddad S, Kupchak P, Dharsee M, Nuin PS, Evans KR, Jung K, Stephan C, Fleshner NE and Yousef GM: MicroRNA signature helps distinguish early from late biochemical failure in prostate cancer. Clin Chem 59(11): 1595-1603, 2013.

17 Schubert M, Spahn M, Kneitz S, Scholz CJ, Joniau S, Stroebel $\mathrm{P}$, Riedmiller H and Kneitz B: Distinct microRNA expression profile in prostate cancer patients with early clinical failure and the impact of let-7 as prognostic marker in high-risk prostate cancer. PLoS One 8(6): e65064, 2013.

18 Song $\mathrm{C}$, Chen $\mathrm{H}$, Wang $\mathrm{T}$, Zhang $\mathrm{W}, \mathrm{Ru} \mathrm{G}$ and Lang J: Expression profile analysis of microRNAs in prostate cancer by next-generation sequencing. Prostate 75(5): 500-516, 2015.

19 Spahn M, Kneitz S, Scholz CJ, Stenger N, Rudiger T, Strobel P, Riedmiller $\mathrm{H}$ and Kneitz B: Expression of microRNA-221 is progressively reduced in aggressive prostate cancer and metastasis and predicts clinical recurrence. Int J Cancer 127(2): 394-403, 2010.

20 Nam RK, Amemiya Y, Benatar T, Wallis CJ, Stojcic-Bendavid J, Bacopulos S, Sherman C, Sugar L, Naeim M, Yang W, Zhang A, Klotz LH, Narod SA and Seth A: Identification and Validation of a Five MicroRNA Signature Predictive of Prostate Cancer Recurrence and Metastasis: A Cohort Study. J Cancer 6(11): 1160-1171, 2015.

21 Austin PC and Tu JV: Bootstrap Methods for Developing Predictive Models. The American Statistician 55(2): 131-137, 2004.

22 Pickl JM, Tichy D, Kuryshev VY, Tolstov Y, Falkenstein M, Schuler J, Reidenbach D, Hotz-Wagenblatt A, Kristiansen G, Roth W, Hadaschik B, Hohenfellner M, Duensing S, Heckmann D and Sültmann H: Ago-RIP-Seq identifies Polycomb repressive complex I member CBX7 as a major target of miR-375 in prostate cancer progression. Oncotarget 7(37): 59589-59603, 2016.

23 Wach S, Al-Janabi O, Weigelt K, Fischer K, Greither T, Marcou M, Theil G, Nolte E, Holzhausen HJ, Stöhr R, Huppert V, Hartmann A, Fornara P, Wullich B and Taubert H: The combined serum levels of miR-375 and urokinase plasminogen activator receptor are suggested as diagnostic and prognostic biomarkers in prostate cancer. Int J Cancer 137(6): 1406-1416, 2015.

24. Karasek P, Gablo N, Hlavsa J, Kiss I, Vychytilova-Faltejskova P, Hermanova M, Kala Z, Slaby O and Prochazka V: Preoperative Plasma miR-21-5p is a Sensitive Biomarker and Independent Prognostic Factor in Patients with Pancreatic Ductal Adenocarcinoma Undergoing Surgical Resection. Cancer Genomics Proteomics (4): 321-327, 2018.

25 Kachakova D, Mitkova A, Popov E, Popov I, Vlahova A, Dikov T, Christova S, Mitev V, Slavov C and Kaneva R: Combinations of serum prostate-specific antigen and plasma expression levels of let-7c, miR-30c, miR-141, and miR-375 as potential better diagnostic biomarkers for prostate cancer. DNA Cell Biol 34(3): 189-200, 2015.

26 Huang X, Yuan T, Liang M, Du M, Xia S, Dittmar R, Wang D, See W, Costello BA, Quevedo F, Tan W, Nandy D, Bevan GH, Longenbach S, Sun Z, Lu Y, Wang T, Thibodeau SN, Boardman
L, Kohli M and Wang L: Exosomal miR-1290 and miR-375 as prognostic markers in castration-resistant prostate cancer. Eur Urol 67(1): 33-41, 2015.

27 Selth LA, Das R, Townley SL, Coutinho I, Hanson AR, Centenera MM, Stylianou N, Sweeney K, Soekmadji C, Jovanovic L, Nelson CC, Zoubeidi A, Butler LM, Goodall GJ, Hollier BG, Gregory PA and Tilley WD: A ZEB1-miR-375YAP1 pathway regulates epithelial plasticity in prostate cancer. Oncogene 36(1): 24-34, 2017.

28 Zehentmayr F, Hauser-Kronberger C, Zellinger B, Hlubek F, Schuster C, Bodenhofer U, Fastner G, Deutschmann H, Steininger P, Reitsamer R, Fischer T and Sedlmayer F: Hsa-miR375 is a predictor of local control in early stage breast cancer. Clin Epigenetics 8: 28, 2016.

29 Yan JW, Lin JS and He XX: The emerging role of miR-375 in cancer. Int J Cancer 135(5): 1011-1018, 2014.

30 Yang X, Du WW, Li H, Liu F, Khorshidi A, Rutnam ZJ and Yang BB: Both mature miR-17-5p and passenger strand miR-17$3 p$ target TIMP3 and induce prostate tumor growth and invasion. Nucleic Acids Res 41(21): 9688-9704, 2013.

31 Shan SW, Fang L, Shatseva T, Rutnam ZJ, Yang X, Du W, Lu WY, Xuan JW, Deng Z and Yang BB: Mature miR-17-5p and passenger miR-17-3p induce hepatocellular carcinoma by targeting PTEN, GalNT7 and vimentin in different signal pathways. J Cell Sci 126(Pt 6): 1517-1530, 2013.

32 Ma MZ, Zhang Y, Weng MZ, Wang SH, Hu Y, Hou ZY, Qin YY, Gong W, Zhang YJ, Kong X, Wang JD and Quan ZW: Long Noncoding RNA GCASPC, a Target of miR-17-3p, Negatively Regulates Pyruvate Carboxylase-Dependent Cell Proliferation in Gallbladder Cancer. Cancer Res 76(18): 5361-5371, 2016.

$33 \mathrm{Li} \mathrm{H}$ and Yang BB: Stress response of glioblastoma cells mediated by miR-17-5p targeting PTEN and the passenger strand miR-17-3p targeting MDM2. Oncotarget 3(12): 1653-1668, 2012.

34 Jin YY, Andrade J and Wickstrom E: Non-Specific Blocking of miR-17-5p Guide Strand in Triple Negative Breast Cancer Cells by Amplifying Passenger Strand Activity. PLoS One 10(12): e0142574, 2015.

35 Zhu J, Dong H, Zhang Q and Zhang S: Combined assays for serum carcinoembryonic antigen and microRNA-17-3p offer improved diagnostic potential for stage I/II colon cancer. Mol Clin Oncol 3(6): 1315-1318, 2015.

36 Zhang X, Ladd A, Dragoescu E, Budd WT, Ware JL and Zehner ZE: MicroRNA-17-3p is a prostate tumor suppressor in vitro and in vivo, and is decreased in high grade prostate tumors analyzed by laser capture microdissection. Clin Exp Metastasis 26(8): 965-979, 2009.

37 Nakata W, Uemura M, Sato M, Fujita K, Jingushi K, Ueda Y, Kitae K, Tsujikawa K and Nonomura N: Expression of miR-27a$3 \mathrm{p}$ is an independent predictive factor for recurrence in clear cell renal cell carcinoma. Oncotarget 6(25): 21645-21654, 2015.

38 Jiang X, Du L, Wang L, Li J, Liu Y, Zheng G, Qu A, Zhang X, Pan $\mathrm{H}$, Yang $\mathrm{Y}$ and Wang C: Serum microRNA expression signatures identified from genome-wide microRNA profiling serve as novel noninvasive biomarkers for diagnosis and recurrence of bladder cancer. Int J Cancer 136(4): 854-862, 2015.

39 Jiang X, Du L, Duan W, Wang R, Yan K, Wang L, Li J, Zheng G, Zhang X, Yang Y and Wang C: Serum microRNA expression signatures as novel noninvasive biomarkers for prediction and prognosis of muscle-invasive bladder cancer. Oncotarget 7(24): 36733-36742, 2016. 
40 Zhou L, Liang X, Zhang L, Yang L, Nagao N, Wu H, Liu C, Lin S, Cai G and Liu J: MiR-27a-3p functions as an oncogene in gastric cancer by targeting BTG2. Oncotarget 7(32): 5194351954, 2016.

$41 \mathrm{Wu}$ XZ, Wang KP, Song HJ, Xia JH, Jiang Y and Wang YL: MiR-27a-3p promotes esophageal cancer cell proliferation via F-box and WD repeat domain-containing 7 (FBXW7) suppression. Int J Clin Exp Med 8(9): 15556-15562, 2015.

42 Wang WS, Liu LX, Li GP, Chen Y, Li CY, Jin DY and Wang XL: Combined serum CA19-9 and miR-27a-3p in peripheral blood mononuclear cells to diagnose pancreatic cancer. Cancer Prev Res (Phila) 6(4): 331-338, 2013.

43 Vychytilova-Faltejskova P, Radova L, Sachlova M, Kosarova Z, Slaba K, Fabian P, Grolich T, Prochazka V, Kala Z, Svoboda M, Kiss I, Vyzula R and Slaby O: Serum-based microRNA signatures in early diagnosis and prognosis prediction of colon cancer. Carcinogenesis 37(10): 941-950, 2016.

$44 \mathrm{Xu} \mathrm{W,} \mathrm{Liu} \mathrm{M,} \mathrm{Peng} \mathrm{X,} \mathrm{Zhou} \mathrm{P,} \mathrm{Zhou} \mathrm{J,} \mathrm{Xu} \mathrm{K,} \mathrm{Xu} \mathrm{H} \mathrm{and} \mathrm{Jiang}$ $S$ : $m i R-24-3 p$ and miR-27a-3p promote cell proliferation in glioma cells via cooperative regulation of MXI1. Int J Oncol 42(2): 757-766, 2013.

45 Zhao N, Sun H, Sun B, Zhu D, Zhao X, Wang Y, Gu Q, Dong $\mathrm{X}$, Liu F, Zhang Y and Li X: miR-27a-3p suppresses tumor metastasis and VM by down-regulating VE-cadherin expression and inhibiting EMT: an essential role for Twist-1 in HCC. Sci Rep 6: 23091, 2016.

46 Chen Z, Liu X, Hu Z, Wang Y, Liu M, Liu X, Li H, Ji R, Guo $\mathrm{Q}$ and Zhou Y: Identification and characterization of tumor suppressor and oncogenic miRNAs in gastric cancer. Oncol Lett 10(1): 329-336, 2015.

47 Li SP, Xu HX, Yu Y, He JD, Wang Z, Xu YJ, Wang CY, Zhang HM, Zhang RX, Zhang JJ, Yao Z and Shen ZY: LncRNA HULC enhances epithelial-mesenchymal transition to promote tumorigenesis and metastasis of hepatocellular carcinoma via the miR-200a-3p/ZEB1 signaling pathway. Oncotarget 7(27): 4243142446, 2016.

48 Xie K, Wang C, Qin N, Yang J, Zhu M, Dai J, Jin G, Shen H, $\mathrm{Ma} \mathrm{H}$ and $\mathrm{Hu} \mathrm{Z}$ : Genetic variants in regulatory regions of microRNAs are associated with lung cancer risk. Oncotarget 7(30): 47966-47974, 2016.

49 Della Vittoria SG, Calura E, Di MM, Romualdi C, Beltrame L, Malapelle U, Troncone G, De Stefano A, Pepe S, De Placido S, D'Incalci M, Marchini S and Carlomagno C: Analysis of differential miRNA expression in primary tumor and stroma of colorectal cancer patients. Biomed Res Int 2014: 840921, 2014.

50 Vojtechova Z, Sabol I, Salakova M, Smahelova J, Zavadil J, Turek L, Grega M, Klozar J, Prochazka B and Tachezy R: Comparison of the miRNA profiles in HPV-positive and HPVnegative tonsillar tumors and a model system of human keratinocyte clones. BMC Cancer 16: 382, 2016.

51 Wang X, Jiang F, Song H, Li X, Xian J and Gu X: MicroRNA200a-3p suppresses tumor proliferation and induces apoptosis by targeting SPAG9 in renal cell carcinoma. Biochem Biophys Res Commun 470(3): 620-626, 2016.

52 Berthois Y, Delfino C, Metellus P, Fina F, Nanni-Metellus I, Al AH, Pirisi V, Ouafik L and Boudouresque F: Differential expression of miR200a-3p and miR21 in grade II-III and grade IV gliomas: evidence that miR200a-3p is regulated by $\mathrm{O}(6)$ methylguanine methyltransferase and promotes temozolomide responsiveness. Cancer Biol Ther 15(7): 938-950, 2014.
53 Liu L, Zou J, Wang Q, Yin FQ, Zhang W and Li L: Novel microRNAs expression of patients with chemotherapy drugresistant and chemotherapy-sensitive epithelial ovarian cancer. Tumour Biol 35(8): 7713-7717, 2014.

54 Li D, Li C, Xu Y, Xu D, Li H, Gao L, Chen S, Fu L, Xu X, Liu Y, Zhang X, Zhang J, Ming $H$ and Zheng L: Differential Expression of microRNAs in the Ovaries from LetrozoleInduced Rat Model of Polycystic Ovary Syndrome. DNA Cell Biol 35(4): 177-183, 2016.

55 Tomofuji T, Yoneda T, Machida T, Ekuni D, Azuma T, Kataoka $\mathrm{K}$, Maruyama T and Morita M: MicroRNAs as serum biomarkers for periodontitis. J Clin Periodontol 43(5): 418-425, 2016.

$56 \mathrm{Li} \mathrm{B}$, Zhou X, Chen L, Feng C and Li T: (Expression of microRNAs in lung homogenates in rats with chronic obstructive pulmonary disease). Zhonghua Wei Zhong Bing Ji Jiu Yi Xue 26(12): 905-909, 2014.

57 Truettner JS, Katyshev V, Esen-Bilgin N, Dietrich WD and Dore-Duffy P: Hypoxia alters MicroRNA expression in rat cortical pericytes. Microrna 2(1): 32-44, 2013.

58 Zavadil $\mathrm{J}$ and Bottinger EP: TGF-beta and epithelial-tomesenchymal transitions. Oncogene 24(37): 5764-5774, 2005.

59 Wang AS, Chen $\mathrm{CH}$, Chou YT and Pu YS: Perioperative changes in TGF-beta1 levels predict the oncological outcome of cryoablation-receiving patients with localized prostate cancer. Cryobiology 73(1): 63-68, 2016.

$60 \mathrm{Wu}$ CT, Hsieh CC, Yen TC, Chen WC and Chen MF: TGF-beta1 mediates the radiation response of prostate cancer. J Mol Med (Berl) 93(1): 73-82, 2015.

61 Kristensen H, Thomsen AR, Haldrup C, Dyrskjøt L, Høyer S, Borre M, Mouritzen P, Ørntoft TF and Sørensen KD: Novel diagnostic and prognostic classifiers for prostate cancer identified by genome-wide microRNA profiling. Oncotarget 7(21): 30760-30771, 2016.

62 Stephenson AJ, Kattan MW, Eastham JA, Dotan ZA, Bianco FJ Jr, Lilja $\mathrm{H}$ and Scardino PT: Defining biochemical recurrence of prostate cancer after radical prostatectomy: a proposal for a standardized definition. J Clin Oncol 24(24): 3973-3978, 2006.

63 Boorjian SA, Thompson RH, Tollefson MK, Rangel LJ, Bergstralh EJ, Blute ML and Karnes RJ: Long-term risk of clinical progression after biochemical recurrence following radical prostatectomy: the impact of time from surgery to recurrence. Eur Urol 59(6): 893-899, 2011.

64 Nam RK, Benatar T, Wallis CJ, Amemiya Y, Yang W, Garbens A, Naeim M, Sherman C, Sugar L and Seth A: MiR-301a regulates E-cadherin expression and is predictive of prostate cancer recurrence. Prostate 76(10): 869-884, 2016.

65 Tsuchiyama K, Ito H, Taga M, Naganuma S, Oshinoya Y, Nagano K, Yokoyama $\mathrm{O}$ and Itoh $\mathrm{H}$ : Expression of microRNAs associated with Gleason grading system in prostate cancer: miR$182-5 \mathrm{p}$ is a useful marker for high grade prostate cancer. Prostate 73(8): 827-834, 2013.

66 Walter BA, Valera VA, Pinto PA and Merino MJ: Comprehensive microRNA Profiling of Prostate Cancer. J Cancer 4(5): 350-357, 2013. 